\title{
How the Jefferson Physical Labopatory came to be
}

\author{
The first building in America dedicated to physics opened \\ its doors 100 years ago: "furnished in the plainest possible manner, but provided \\ with everything which intelligent forethought could plan."
}

\section{Gerald Holton}

A hundred years ago, the first building in the western hemisphere designed for research and teaching in physics opened its doors. The consequences of such an event are of very different interest to different groups. The physicist will ask about the advances made in Jefferson Lab, and in nearby structures added later, by its faculty, students and collaborators: Lyman lines and broken symmetries; dimensional analysis and nuclear magnetic resonance; the muon and the $21-\mathrm{cm}$ line; tests of the equivalence principle and of quantum electrodynamics; the acoustics of buildings and of violins; precise mass spectra, and the phase diagrams of hundreds of substances; the theory of magnetism and quadrupole moments; medical uses of particle beams and determinations of the structure of the ionosphere; the Duane-Hunt law of $\mathrm{x}$ ray emission, and Russell-Saunders coupling; the research and teaching of

Gerald Holton is Mallinckrodt Professor of Physics, and professor of history of science at Harvard University
Edwin C. Kemble, America's first quantum theorist; and the latest in mathematical physics, condensed-matter theory or elementary-particle interactions.

An industrialist might be more interested in other advances, achieved in Jefferson Lab or spun off from work done there: communication-engineering devices and computer design; industrial diamonds and atomic clocks; the large-sheet polarizer; the light-weight phonograph pickup; piezoelectric and magnetostriction devices, and so on.

An educator or administrator may be more interested in the large number of students, including some 900 living alumni, who received their advanced degrees in physics from its faculty, and in the further outreach through many widely used textbooks at all levels, from high-school projects to advanced monographs.

The historian, however, is likely to ask about this building-this somewhat time-worn grande dame in need of refreshments: How did it come to be?

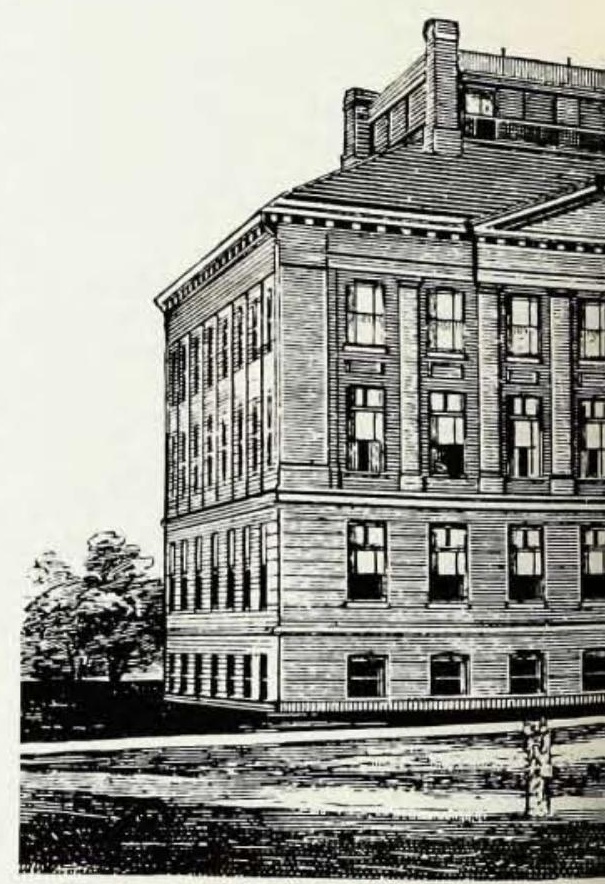


Why at that time, and why in that place? We shall see that the construction of the building at Harvard was really a rather improbable event, and also that the story is not without some contemporary parallels.

In terms of the physics of their time, most scientists were certainly not clamoring for such a structure in the late 1870 s and early 1880 s. That period was a sort of halfway house between great accomplishments: on the one hand the grand syntheses of the past decadesthe law of conservation of energy, and Maxwell's treatise joining electricity, magnetism, and light-and on the other hand, the excitement to come a decade or two later, with x-rays, radioactivity and the electron. While the Jefferson Lab was being planned and built, physics was really waiting for something to happen to put it to good use. This impression is borne out by glancing through the volume for 1884 of the main journals of the day: With rare exceptions, the articles do not rise above the level of useful but pedestrian investigation.

\section{An imposing temple of science}

When this temple of science was opened it looked quite imposing -210 feet long and four stories high. As President Charles W. Eliot of Harvard described it, the building was "furnished throughout in the plainest possible manner, but provided with everything to facilitate physical research which intelligent forethought could plan."
But it also must have looked rather overdesigned in terms of the manpower available in the US. There was only a small handful of top quality men: Henry A. Rowland, J. Willard Gibbs, and young Albert A. Michelson, none of them at Harvard. In the whole country there were, during the period of 1870 to 1893, fewer than 50 physicists in America who had an average rate of publication of even one paper per year or higher. Of these, less than half had PhDs, some from Yale, Johns Hopkins, or Harvard, but mostly earned at foreign universities. Moreover, most university presidents were not interested in furthering research. As Eliot put it, ${ }^{2}$ that activity would require "fanatical zeal" if one's main obligation, namely "regular and assiduous class teaching," were not to be neglected. Francis Walker of MIT agreed, saying ${ }^{3}$ as late as 1889: "Our aim should be the mind of the student, not scientific discovery, not professional accomplishment."

There was also not yet a professional physical society nor a national physics journal. There were hardly any jobs for trained physicists except in teaching, and that would have to be either elementary physics in the classical college curriculum (a mandatory course of long standing, with hapless Harvard freshmen getting their Aristotelian physics at least as early as 1642), or else physics taught with an eye to applied science in schools set up separately from the College, such as Harvard's Lawrence Scientific School (established in 1847), Yale's Sheffield
Scientific School (1847), and MIT (1865).

But in the search for historical causation, one should not underestimate the role that a concatenation of benign accidents can play. President Daniel C. Gilman's leadership in starting The Johns Hopkins University in 1876, with the first systematic program in "advanced study and research," might by itself not have been an urgent example to anyone else. President Eliot's mission to bring to Harvard a modern-day education, an enthusiasm he had first discovered as an instructor at MIT, also did not point inevitably to the realization of a research laboratory at Harvard. John Trowbridge, if he had been a professor at some other university, might not have perservered against the odds he found at Harvard. On arriving as an assistant professor in 1870 , he certainly did not find Joseph Lovering, the senior professor in the department, an ally in his plans to make Harvard an institution for research as well as teaching. As Edwin H. Hall, who joined in 1881, later put it: ${ }^{4}$ "I doubt whether Professor Lovering ever made an original experiment, or any experiment not required for his lectures.... As a young man he had been a student of Divinity, and as a college professor he seems to have felt no more called upon to extend the domain of physics than as a preacher he would have felt obliged to add a chapter to the Bible. ... I once proposed to him, probably about 1884 , that we should drop a certain textbook from

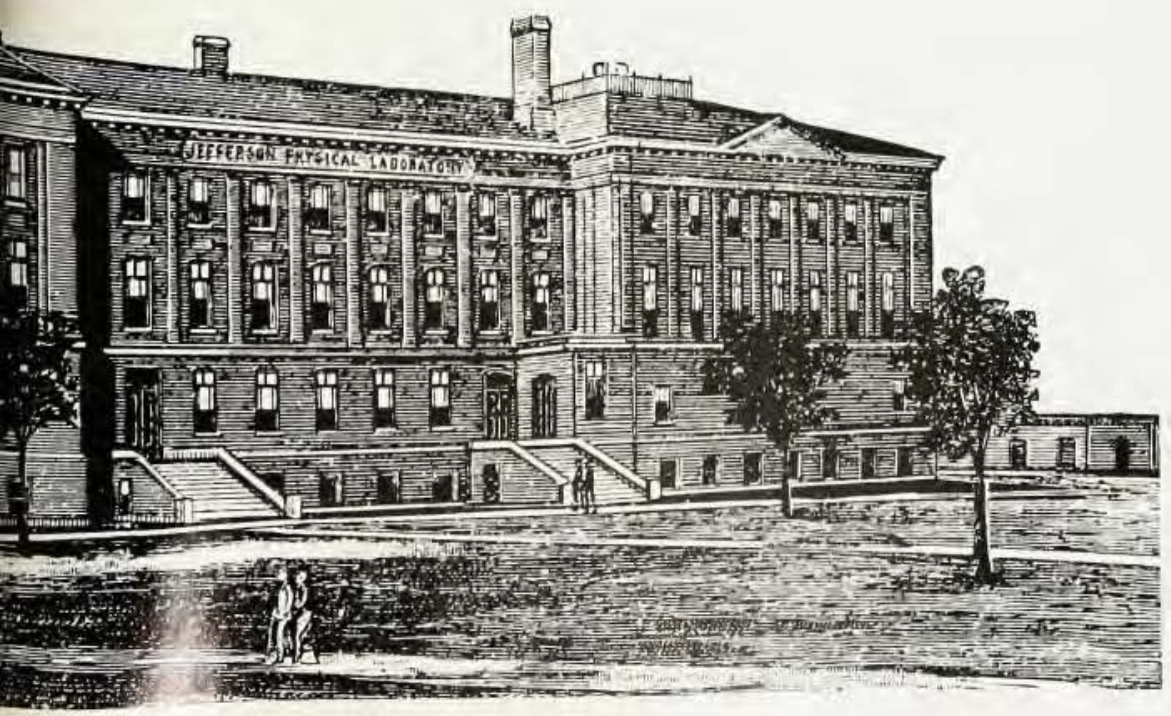

The Jefferson Physical Laboratory at Harvard University soon after it opened in 1884. It allowed physics instruction to take place not by rote and by books, but in the laboratory. "with objects and instruments in hand. 


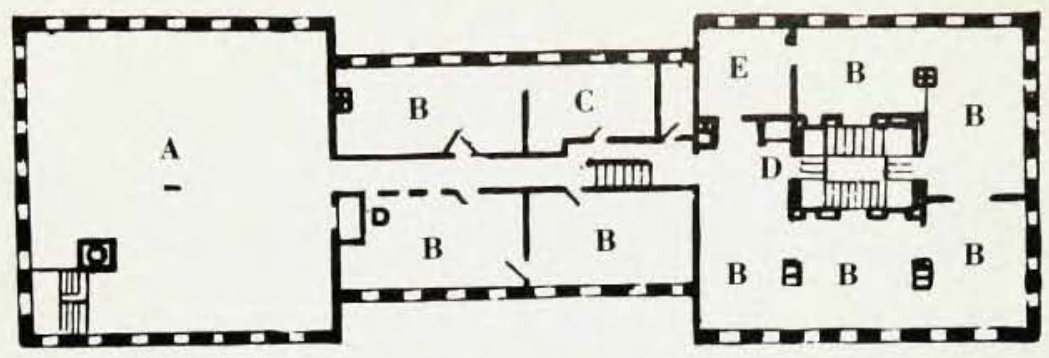

THIRD FLOOR

A Elementary laboratory: B Special investigations; C Library; D Elevators; E Photographic chamber.

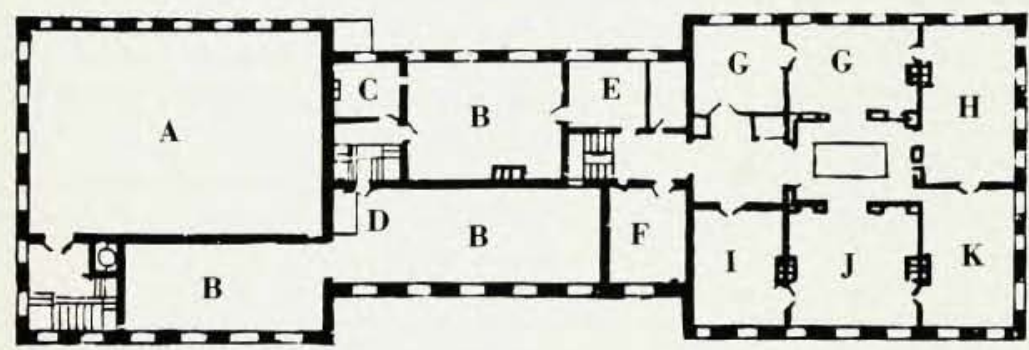

SECOND FLOOR

A Lecture room; B Cabinets; C Professor's room; D Elevator; E Professor's room; F Library; G Optical room; H Rumford lecture room: I Sound laboratory; J Special investigations; K Chemical laboratory: R Recitation room.

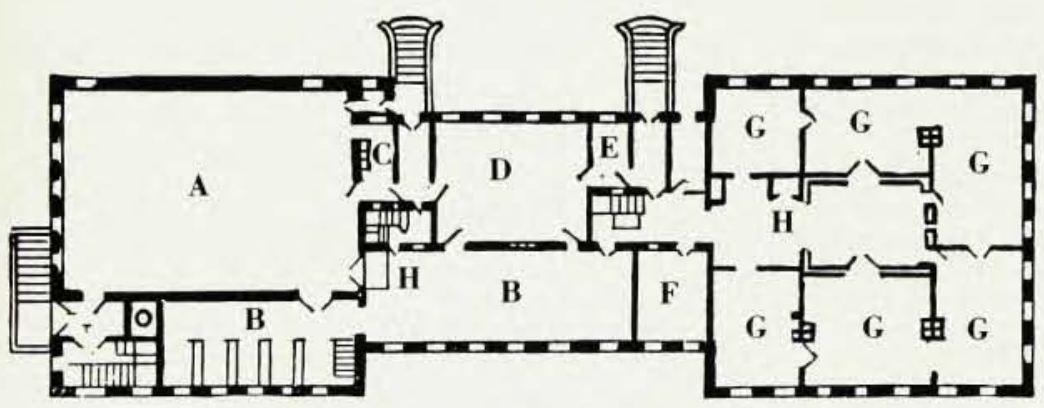

FIRST FLOOR

A Space under lecture room; B Cabinets; C Preparation room; D Recitation room; E Professor's room; F Balance room; G Special investigations; H Elevators.
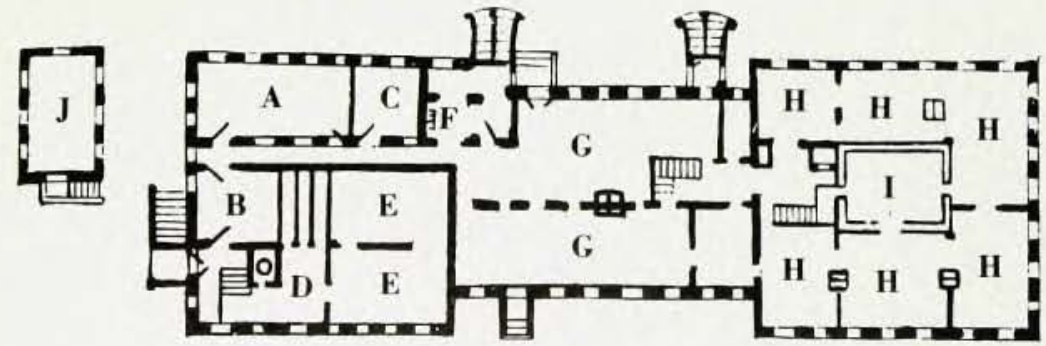

BASEMENT

A Workshop; B Forge; C Battery room; D Fire room; E Coal; F Mercury room: G Receiving room; H Special investigations; I Constant-temperature room: J Engine room. our list of admission requirements. 'Why?,' he asked. 'Because,' I replied, 'it is behind the times.' "That is just why I like it,' he said, 'bringing it up to the times means putting in a lot of improper matter." "

Trowbridge changed all that. From 1877 on, we find him planning and scheming brilliantly to have a laboratory built in which to teach physics with laboratory exercises, "with objects and instruments in hand." Moreover he insisted that physics instruction required immersion in research as well. Harvard had already an herbarium, a Museum of Comparative Zoology and an astronomical observatory. Trowbridge asked that the analogy be extended to the case of physics.

\section{A campaign document}

The important break came when Johns Hopkins acquired its first large shipments of European scientific equipment, mostly bought by Trowbridge's friend, Henry A. Rowland, for investigations and not, as Rowland put it, "for amusing children." Adopting a strategy not new then and not forgotten since, Trowbridge wrote to Gilman: "I shall use your list as a campaign document" in raising an endowment for a research laboratory at Harvard. When Trowbridge published a collaborative paper surveying laboratory apparatus in the United States, he could show that the newly established Johns Hopkins University owned almost seven times as much physics apparatus as did Harvard.

By 1880 Trowbridge had been given his hunting license to seek the funds for 


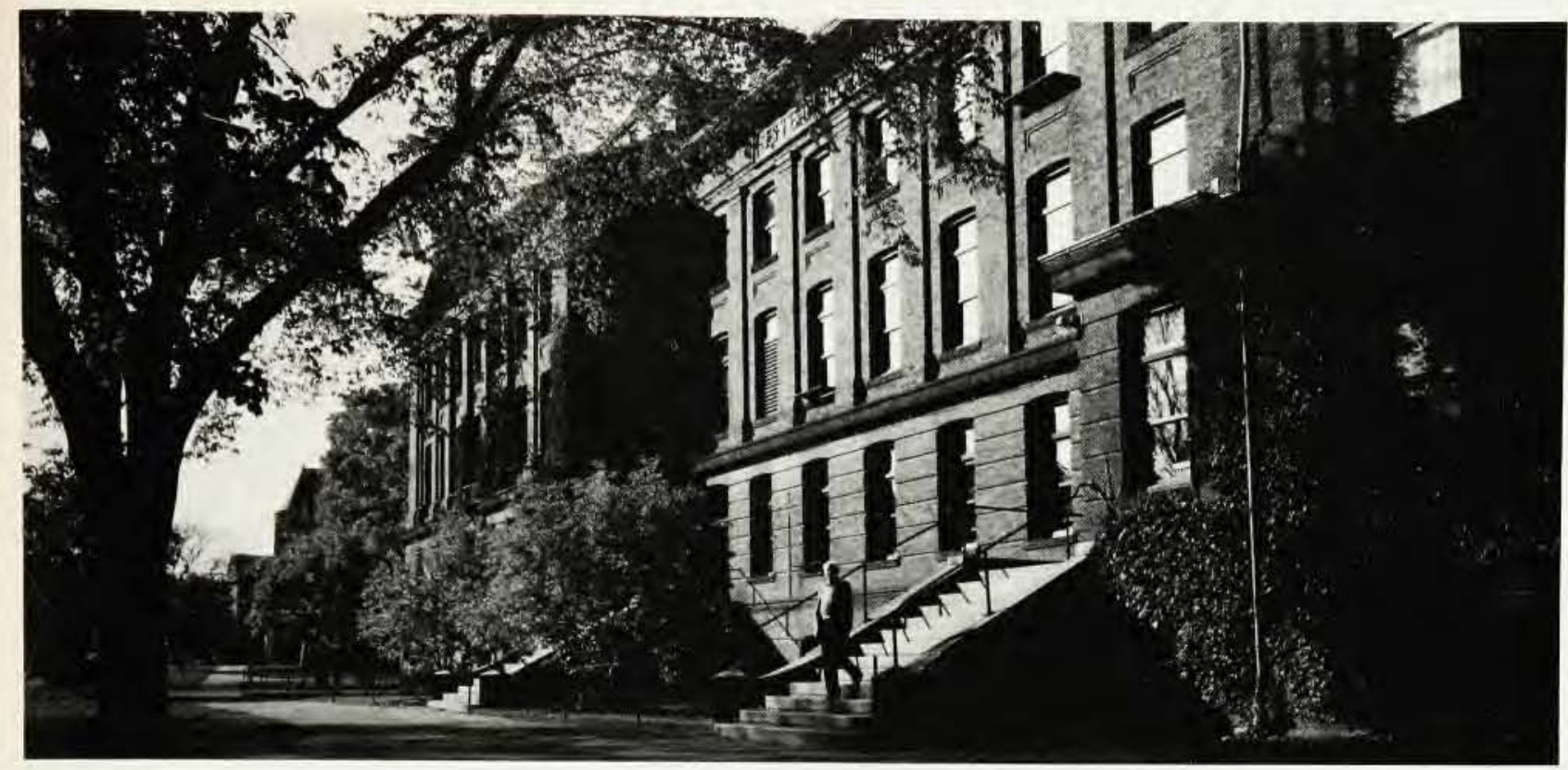

The Jefferson lab in 1984, a hundred years after it opened. "A somewhat time-worn grande dame, in need of refreshments," its exterior remains almost unchanged-the red brick had originally been a problem because of its slightly magnetic iron oxide content.

construction and endowment of operations. An anonymous "friend of the University" came forward to give $\$ 115000$ on the condition that another $\$ 75000$ would be raised to cover running costs. The anonymous donor turned out to be the Boston businessman Thomas Jefferson Coolidge (class of 1850). The name of the Jefferson Laboratory honors Coolidge's ancestor, the President who was not only a vocal supporter of science in America but also a publishing contributor to it. The endowment for running costs was raised through the generosity of Alexander Agassiz. Thus, as so often in the US, the project became a reality when a person with a vision met both an administrator who provided encouragement and philanthropists who recognized a moment of leadership.

When the building opened in the fall of 1884 , its very design and "plainest possible" furnishings-down to the unpainted brick walls inside - were statements opposing the ornate European style of laboratory construction. Standing 300 feet from the nearest street at the northern end of the campus, outside the built-up area of Harvard Yard, the big red building must have seemed like some curious fortification. Inside, separated by a one-foot gap from all main walls, a 75 foot-high free-standing tower served as the mounting wall for the galvanometers and other electrical measuring equipment of the time. To make them swing true, all magnetic building materials har been kept to a minimumalthougl the brick itself turned out to be slif ly magnetic, and thus vitiated much of the work that went into making the rest nonmagnetic.

\section{'What is electricity?'}

A building is the tangible metaphor of an idea in its architect's mind. In this case, it embodied Trowbridge's passionate vision of what the physics of the future would bring and how to reach it. That conception came out most clearly in his talk, "What is electricity?" which Trowbridge gave within days of the opening of the building. $^{5}$ He began:

I must express my conviction that we shall never know what electricity is, anymore than we shall know what energy is. What we shall be able probably to discover is the relationship between electricity, magnetism, light, heat, gravitation, and the attracting force which manifests itself in chemical changes. We have one great guiding principle which, like the pillar of cloud by day and the pillar of fire by night, will conduct us, as Moses and the Israelites were once conducted, to an eminence from which we can survey the promised scientific future. That principle is the conservation of energy.... The ancients had a god for every great manifestation of nature - a god of peace, a god of war, a god of the land, a god of the sea. Fifty years ago scientific men were like the ancients. There was a force attached to every phenomenon of Nature... But what we are to have in the future is a treatise which will show the mechanical relations of gravitation, of socalled chemical attracting force and electrical attracting force, and the manifestations of what we call radiant energy.

Just how were these relations to be found? This was where the warrant for the new laboratory entered. "Let us strive with the most powerful instruments we have, to survey the promised land which is undoubtedly to be the possession of those who come after us." In this way, we shall "see the relations of electrical and magnetic attraction to the attraction of gravitation and to what we call chemical attraction." Indeed, all the forces of nature would be as one. The old monistic dream of science would triumph at last.

For example, consider thermoelectricity. "I have often thought that the jostling, so to speak, of these ultimate molecules of two metals at definite temperatures might form a scientific unit of electro-motive force in the future science of physical chemistry. Look at the great field for investigation there is in the measurement of what we call electro-motive force." Some future "great generalizer, like Sir Isaac Newton," would surely come along and use our store of patiently gathered data, to lay bare and explain the "ultimate motions of the molecular world."

Moving on to still more daunting problems, Trowbridge said, "We seldom reflect that gravitation is as great a mystery as electrical attaction." What is the relation between them? "I have often asked myself ... can not the refined instruments and methods of the electrical science of the present aid us 


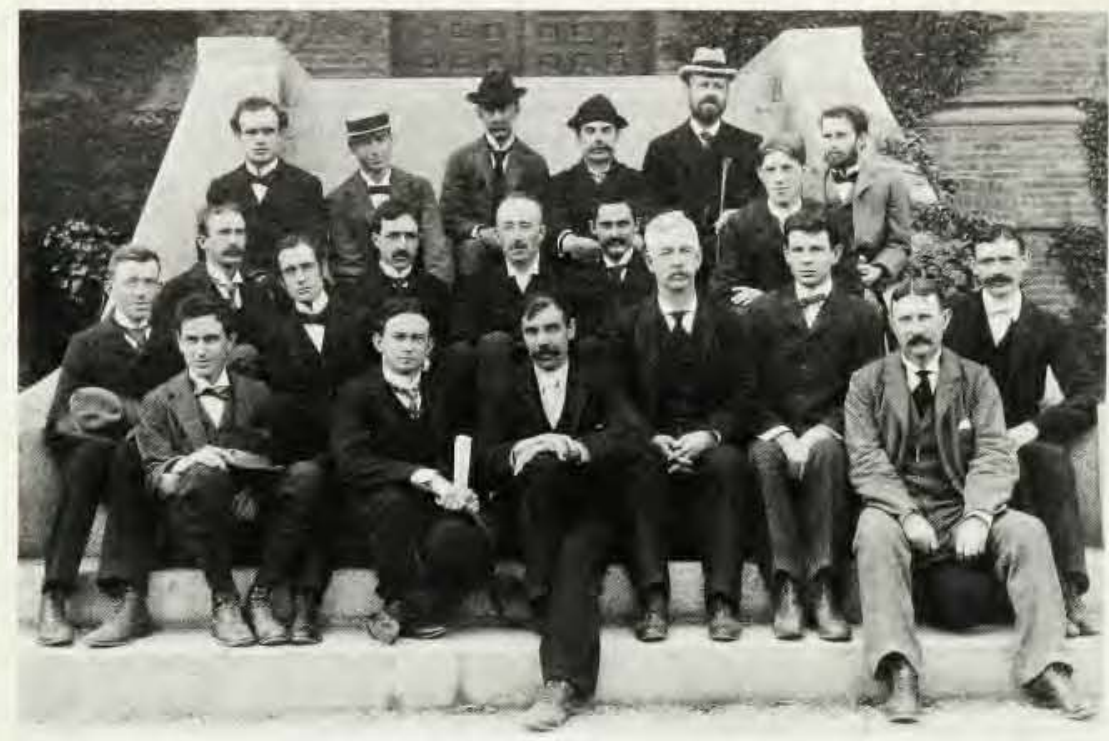

in more prominent lines of research? Should we not expect that, when two balls of copper, for instance, are suddenly removed from each other, a difference of electrical potential should manifest itself?"

What is called for here is "a delicate electrometer." To be sure, so far experiments along this line have given negative results. But that is only a challenge to our ingenuity: "We are like blind men in a great field of energy striving to ascertain the configuration about us with only three senses-the galvanometer sense, the electrometer sense, and the voltameter sense." If one could add to these senses, one might "become sensible of every change among atoms and molecules." And venturing to the very edge of the precipice, Trowbridge added: "Suppose that the quick passing of what we call life from the body into another shape or state of existence should be sensible as a reaction in electrical and magnetic effects.

All these dreams had been thwarted so far by the same obstacle. "We have arrived at that stage in our study of electricity where our instruments are too coarse to enable us to extend our investigations.... Is not the physicist of the future to have instruments delicate enough .... to discover beats of light, as we now discover those of sound-[or] an apparatus which will measure the difference of electrical potential produced by the breaking up of composite grouping of molecules?"

At the end of his talk. Trowbridge confessed he had failed to answer his question, "What is electricity?" To be sure. But he had made a confession that now sounds curious indeed in the setting of his physics, yet is still perfectly recognizable in the context of ours. The chief task was to find a way by which to glimpse experimental evi- dence of the unification of forces. And for that purpose, he thought, sensitive detectors are the key. The research wing of the Jefferson Lab was designed in every detail with that aim in mind, the free-standing tower serving to push down the noise level, what he called ${ }^{6}$ "prejudicial vibrations" set up by the wind or the movement of faculty and students. Indeed, the whole building was to be a giant detector, to test his premature grand-unification ideas.

\section{A vision for the future}

Trowbridge's dream was not an unreasonable one if one considers it an extrapolation of the trajectory of 19thcentury physics - from Alessandra Volta, Hans Christian Oersted, Michael Faraday and André-Marie Ampere to James Clerk Maxwell, and from Count Rumford, Julius Robert Mayer and James Prescott Joule to Hermann von Helmholtz. Nor was Trowbridge alone in his passion. His friend, Rowland, at Johns Hopkins, addressing the Electrical Conference in September 1884, spoke $^{7}$ of the need for a theory of matter that would combine electricity, magnetism, light, gravitation, heat and chemical action: "It forms the great problem of the universe... which looms up before us, and before which we stand in awe." To attain results, one condition had to be fulfilled: "Let physical laboratories arise."

If the vision of the future of science was one source of energy behind the project, a second source reinforced it powerfully. To put it simply, it was national pride, hurt by the conditions that had kept research down. The astronomer Simon Newcomb had said in 1874, good scientists in America are thought to be "necessarily of transatlantic origin." In a famous lecture ${ }^{8}$ of 1883. "A plea for pure science," he had spoken for a growing number who were
The Harvard physics department around 1900. Among the department members shown here, sitting with instrument makers and staff on the steps of Jefferson Lab, are: (top row, second from left) Wallace $\mathrm{C}$. Sabine, John Trowbridge (third), Edwin $\mathrm{H}$. Hall (fourth), Benjamin O. Peirce (fifth): (second row, third from left) Theodore Lyman; (bottom row, second from left) George W. Pierce. warning Americans not to glory only in the applications of science. The Age of Electricity had brought the first telephone in 1876, the first good arc light in 1878; in 1879, Thomas Edison's incandescent bulb had lasted a full 40 hours; and all along there were improvements in telegraphy. The excitement caused by these applications was high, and the average man's life was made more pleasant by them. But Rowland thundered that scientists missed in all this the vigor of high ideas:

We are tired of mediocrity, the curse of our country.... We are tired of seeing our countrymen take their science from abroad...

Shall our country be contented to stand by, while other countries lead in the race? Shall we always grovel in the dust, and pick up the crumbs which fall from the rich man's table, considering ourselves richer than he because we have more crumbs, while we forget that he has the cake which is the source of all crumbs? Shall we be swine, to whom the corn and husks are of more value than the pearls? If I read aright the signs of the times: I think we shall not always be contented with our inferior position. From looking down we have almost become blind, but may recover.

$\mathrm{He}$ found it outrageous that this small and thinly populated country should at that time have 400 institutions that called themselves colleges or universities. "The whole earth could hardly support such a number of firstclass institutions. The curse of mediocrity must be upon them, to swarm in such numbers. There must be a cloud of mosquitoes, instead of eagles as they profess." Barely five percent of them had 20 or more faculty members in all 


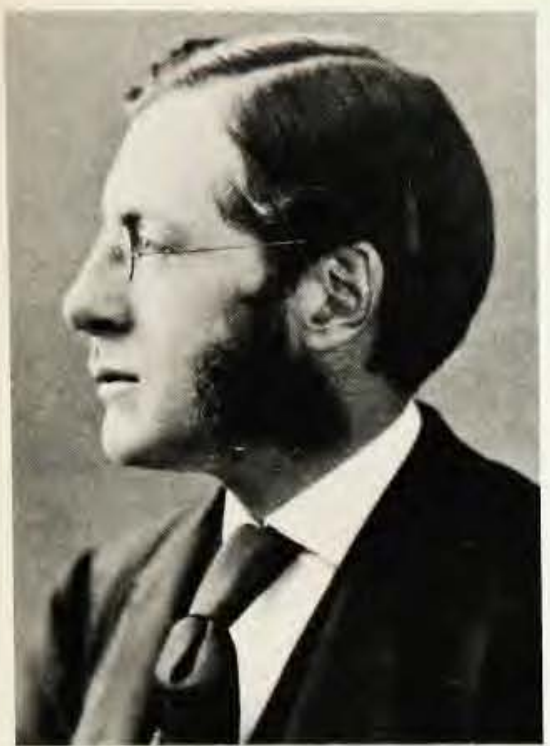

fields, or an endowment for all purposes of over $\$ 500000$. Fewer still had more than 300 students in all fields.

Worst of all, research-minded physicists were poorly dealt with. "Life is short: old age comes quickly, and the amount one pair of hands can do is very limited.... I know of no institution in this country where assistants are supplied to aid directly in research; yet there are many physical problems, especially those requiring exact measurements, which cannot be carried out by one man." Large, well-equipped, well-staffed physical laboratories must be created, on the model of the endowed observatories that have advanced astronomy so well. "The time has even now arrived when such a grand laboratory should be founded." Then indeed a sound science of physics will "arise among us, and make us respected by the nations of the world. ... [I] have the feeling, common to all true Americans, that our country is going forward to a glorious future, when we shall lead the world in the strife for intellectual prizes as we now do in this strife for wealth."

\section{Great expectations}

When the Jefferson Lab opened its doors, both scientific and patriotic hopes must have been focused on it with great expectations. Here at last was a facility with several faculty members (Lovering, Trowbridge, Benjamin O. Peirce, Edwin H. Hall, Harold Whiting and chemist Wolcott Gibbs). There were assistants and students, well-appointed machine shops, an engine room, a battery room, an optical room, a constant-temperature room, a chemical laboratory, a mercury room, a photographic chamber, not to speak of lecture halls, recitation rooms, a library, instrument cabinets, and professors' roums.

Charles W. Eliot,

president of Harvard University at the time the Jefferson lab was built. He espoused the relatively novel view that education should include science and modern languages as well as classics and theology.

\section{John Trowbridge joined the Harvard physics department in 1870. By 1880 , he had persuaded Eliot that physics should be taught in a laboratory; funds were raised and the laboratory was built in four more years}

In truth, for the first few years the fruits reaped at the lab were not outstanding. But there was splendid space there, equipment and hands and funds; some very talented students; and an unflagging sense of mission that kept Trowbridge active for decades.

By the time he retired as director in 1910 , the faculty included Wallace C. Sabine, George W. Pierce, Theodore Lyman and Percy W. Bridgman, all of whom had done their graduate work in the Jefferson Lab (with Lyman and Bridgman getting their bachelor's degrees at Harvard as well).

The building - as all good buildingsproved adaptable to the constantly changing and unforeseeable needs of the research carried on in it. Sabine was able to use the constant-temperature room and the lecture hall for his acoustical studies. The battery room could, early in this century, deliver the potential differences needed for Lyman's spectroscopic discharge tubes. The isolated central tower-less than ideal for the sensitive galvano-magnetic experiments for which it was intended-served well to reduce the vibrational noise when Robert Pound and Glen Rebka came to measure the gravitational redshift of $\gamma$ rays. In the machine shop, staffed with fine craftsmen such as Charles Chase, presses could be built with which Bridgman achieved record pressures.

The physicist as both teacher and superb researcher-a novel idea when Trowbridge had proposed it for the endorsement of Eliot and Coolidgehad become a reality by the early part of our century in a growing number of centers. The groundwork had been laid for this laboratory, together with similar institutions elsewhere in this na tion, to play its role as physics in America was entering on its maturer phase-still propelled by the enthusi-

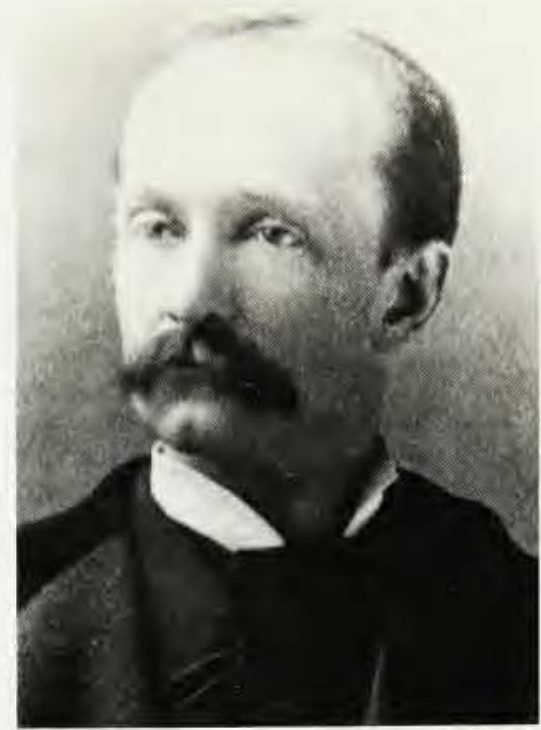

asms to which Trowbridge and Rowland had confessed.

\section{References}

1. C. W. Eliot, Annual Report of the President of Harvard University, 1883-84, p. 43.

2. C. W. Eliot, in The Development of Harvard University, S. E. Morison, ed., Harvard U.P., Cambridge, Mass. (1930), p. 378.

3. C. W. Eliot, Inaugural Address as President of Harvard College; reprinted in $A$ Turning Point in Higher Education, N. M. Pusey, ed., Harvard U.P., Cambridge, Mass. (1969), p. 21

4. E. H. Hall, in The Development of Harvard University, S. E. Morison, ed., Harvard U.P., Cambridge, Mass. (1930), p. 277. In addition to Hall's essay, there are several other useful sources on the Department's history: L. I. Aronovitch, "Towards a New Knowledge of Nature: Physics at Harvard University, 1870 $1910 "$ AB Honors Thesis in History and Science (1983); S, Goldberg, "History of Physics at Harvard University, 19071912," Cambridge, Mass., 1962 (unpublished manuscript); [T. Lyman] The Physical Laboratories of Harvard University. printed at Harvard U.P., Cambridge, Mass. (1932); K. R. Sopka, "Physics at Harvard during the Past Half Century: A Brief Departmental History" (unpublished manuscript). The literature on American science in the 1880 s is large and the scholarship very strong. A good bibliography for a first look can be found in D. J. Kevles, J. L. Sturchio, P. Carroll. Science 209, 27 (1980)

5. J. Trowbridge, The Popular Science Monthly November 1884 , p. 76 ; address before Section B, AAAS, at the "Electrical Conference," Philadelphia, 4 September 1884

6. J. Trowbridge, Science 5, 230 (1885).

7. H. A. Rowland, Address of 8 September 1884, in The Physical Papers of Henry Augustus Rowland, Johns Hopkins U.P. Baltimore, Md (1902), p. 619.

8. H. A. Rowland, Science 2, 242 (1883) delivered at the AAAS meeting, $15 \mathrm{Au}$ gust 1883 . 